\title{
Comparing Buprenorphine-Prescribing Physicians Across Nonmetropolitan and Metropolitan Areas in the United States
}

Lewei (Allison) Lin, MD, MS

Hannab K. Knudsen, $P b D^{3}$

'Addiction Center, Department of Psychiatry, University of Michigan, Ann Arbor, Michigan

${ }^{2}$ Center for Clinical Management Research (CCMR), Veterans Affairs Ann Arbor Healthcare System, Ann Arbor, Michigan

${ }^{3}$ Department of Behavioral Science and Center on Drug and Alcohol Research, University of Kentucky, Lexington, Kentucky

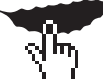

MORE ONLINE

www.annfammed.org
Conflicts of interest: authors report none.

\section{CORRESPONDING AUTHOR}

Lewei (Allison) Lin

Department of Psychiatry

University of Michigan

Building 16, 2nd Floor

2800 Plymouth Road

Ann Arbor, MI 48109

leweil@med.umich.edu

\begin{abstract}
PURPOSE Although there is a tremendous need to increase the use of buprenorphine for the treatment of opioid use disorder in rural areas, little is known about current rural/urban differences in treatment practices. We aimed to examine physician characteristics, treatment practices, and concordance with treatment guidelines among buprenorphine prescribers across different locations of practice.
\end{abstract}

METHODS A national random sample of buprenorphine physician prescribers was surveyed $(n=1,174$, response rate $=33 \%$ ) from July 2014 to January 2017. Analyses examined buprenorphine treatment across locations of practice (categorized as nonmetropolitan, small metropolitan, and large metropolitan).

RESULTS Among buprenorphine prescribers surveyed, $11.2 \%(n=132)$ practiced in nonmetropolitan/rural areas, $32.5 \%(n=382)$ in small metropolitan areas, and $56.2 \%(n=660)$ in large metropolitan areas. Buprenorphine prescribers in nonmetropolitan areas were much more likely to be primary care physicians, accept Medicaid, and less likely to work in an individual practice. Overall, buprenorphine prescribers across the rural/urban continuum were similar in many of their treatment practices, including induction, frequency of visits, dosing, and use of psychosocial treatment, which were generally consistent with buprenorphine treatment recommendations.

CONCLUSIONS There are important differences in characteristics of buprenorphine prescribers in nonmetropolitan areas compared with more urban areas, including the fact that the majority of nonmetropolitan physicians are primary care physicians. Although treatment access in rural areas is an ongoing challenge, buprenorphine treatment practices are similar. Understanding buprenorphine prescribers and their treatment practices may help inform tailored strategies to address treatment needs in different locations.

Ann Fam Med 2019;17:212-220. https://doi.org/10.1370/afm.2384.

\section{INTRODUCTION}

$\mathrm{O}$ pioid use disorder (OUD) has increased rapidly in the United States, leading to increased opioid overdose mortality and many other serious harms. ${ }^{1-4}$ Buprenorphine is a highly effective treatment for OUD; it is associated with decreased mortality and can be delivered by trained physicians in office-based settings. ${ }^{5-7}$ Recent data, however, suggest that there is broad variation with respect to access to buprenorphine treatment, with particularly low availability in nonmetropolitan, or rural, areas in the United States. ${ }^{8,9}$ Although treatment availability has increased across the United States, as of 2017, 56\% of rural counties still did not have a single buprenorphine prescriber, compared with $23 \%$ of urban counties. ${ }^{8}$ As increased resources are being dedicated to increase treatment access, ${ }^{10,11}$ it is critical to understand whether there are differences in physician characteristics and treatment practices between nonmetropolitan and metropolitan areas, which may inform tailored strategies to address treatment needs in these different locations. 
Access to mental health resources and patient factors that differ between nonmetropolitan and urban areas may affect buprenorphine treatment practices and quality. There is less availability of therapists, psychiatrists, and other clinicians in nonmetropolitan areas to treat mental health disorders, which are often comorbid in patients with OUD. ${ }^{12-14}$ Patients in nonmetropolitan areas often travel much longer distances to seek treatment, which has been associated with receiving fewer mental health visits and less guideline-concordant mental health treatment. ${ }^{15}$ Similar challenges arise for OUD treatment, which typically involves frequent long-term visits. The American Society of Addiction Medicine has issued guidance on buprenorphine treatment, in which "improvement in quality of care should be the goal."16 Guidelines recommend that during treatment initiation, also known as the induction period, patients should typically be observed and monitored in physicians' offices. Inductions taking place in the patient's home can be considered if the physician or patient is experienced with the use of buprenorphine. Other recommendations that are consistent with high-quality buprenorphine treatment include regular visits throughout long-term or maintenance treatment, increased frequency of visits in association with clinical instability, individually tailored recommendations for psychosocial therapies, and avoidance of buprenorphine doses $>24$ $\mathrm{mg}$ to mitigate risks of misuse and diversion. ${ }^{16,17}$

A few studies have examined buprenorphine physician characteristics and perceptions among physicians in nonmetropolitan areas, ${ }^{18,19}$ but to our knowledge, there has been no work comparing buprenorphineprescribing physicians in nonmetropolitan areas to those in other areas, and no studies have compared physicians' use of specific treatment practices as indicators of treatment quality. We hypothesized that physicians in nonmetropolitan areas, due to increased distance and fewer resources in these areas, may have different treatment practices during induction and long-term treatment including more home inductions, less frequent visits, and different dosing patterns. The present analysis used survey data from a large random sample of active US buprenorphine prescribers. We assessed differences in physician characteristics across locations of practice (nonmetropolitan, small metropolitan, and large metropolitan) and compared buprenorphine treatment practices and attitudes to better understand typical buprenorphine treatment.

\section{METHODS}

\section{Sample and Data Collection}

A national random sample of 1,174 physicians who prescribe buprenorphine treatment for OUD was recruited from July 2014 to January 2017. The sample was drawn from the May 2014 issue of the US Drug Enforcement Administration's Controlled Substances Act Active Registrants database, which listed all physicians who had met the requirements to prescribe buprenorphine for the treatment of OUD. Prescribers were sampled in each state, according to the proportion of their state's representation in the database. To be eligible for the study, physicians were additionally required to be actively treating at least 1 patient with OUD. Full details on recruitment have been published. ${ }^{20,21}$ The protocol included sending an advance notification letter, express mailing the survey packet, mailing a postcard reminder 2 weeks later, and calling physicians after 6 weeks of nonresponse and sending a second survey packet. Respondents received a check for $\$ 100$ by mail. All research procedures were approved by the University of Kentucky's medical Institutional Review Board.

\section{Measures}

Physicians were categorized into 1 of the 3 following mutually exclusive groups on the basis of their location of practice: large metropolitan, small metropolitan, and nonmetropolitan. Coding was based on the 2013 RuralUrban Continuum (RUC) Codes published by the US Department of Agriculture's Economic Research Service $_{r}^{22}$ which integrates information regarding a county's location in a metropolitan or nonmetropolitan statistical area, population size, and proximity to more populous areas. Physicians' ZIP Codes were linked to US counties using the Federal Information Processing Standards codes published by the US Department of Housing and Urban Development. ${ }^{23}$ Counties were categorized into large metropolitan areas (ie, metropolitan areas with population $\geq 1$ million, RUC code $=1$ ), small metropolitan areas (ie, metropolitan areas with population $<1$ million, RUC codes $=2$ or 3 ), and nonmetropolitan areas (ie, RUC codes $=4$ to 9 ).

Physicians' medical specialties were categorized into 3 mutually exclusive groups of primary care (eg, family medicine, internal medicine), addiction/psychiatry (addiction medicine, addiction psychiatry, or psychiatry alone), and all other specialties. Practice setting was categorized according to whether or not the physician prescribed buprenorphine in individual medical practice $(1=$ yes, $0=$ no). Years were calculated from when the physician began prescribing buprenorphine to the year of the survey. Type of buprenorphine waiver was obtained from the May 2014 Controlled Substances Act Active Registrants database ( $1=$ up to 100 patients, $0=$ up to 30 patients). Payment for office visits was categorized as (1) accepted cash payment only, (2) accepted private insurance but not Medicaid, (3) accepted Medicaid (with or without private insurance; 
nearly all accepted private insurance), and (4) all others (largely US Department of Veterans Affairs physicians). Demographic characteristics included age, sex, and race/ ethnicity. US Census Divisions, based on physicians' addresses, were included. ${ }^{24}$

Key buprenorphine treatment practices were assessed by asking physicians to report the percentage of patients receiving the specific practice in the past year or to describe their typical practices regarding office visits and dosing. Physicians were also asked to describe the resources available within their practice to address patients with complex medical needs, psychiatric needs, and social needs using a 5-point Likert scale ranging from $1=$ strongly disagree to $5=$ strongly agree .

\section{Statistical Analysis}

Data entry and management were supported by the use of Research Electronic Data Capture (REDCap) tools hosted at the University of Kentucky. ${ }^{25}$ After data were exported from REDCap, all statistical

Table 1. Characteristics of US Buprenorphine Prescribers Across Locations of Practice

\begin{tabular}{|c|c|c|c|c|c|c|}
\hline & $\begin{array}{c}\text { Large } \\
\text { Metropolitan } \\
\text { Area }\end{array}$ & $\begin{array}{c}\text { Small } \\
\text { Metropolitan } \\
\text { Area }\end{array}$ & $\begin{array}{l}\text { Nonmetropolitan } \\
\text { Area }\end{array}$ & $\mathbf{N}$ & $\chi^{2}$ or $\mathbf{F}$ & $P$ Value \\
\hline Medical specialty, No. (\%) & & & & 1,149 & 39.09 & $<.001$ \\
\hline Primary care & $215(33.4)$ & $162(42.9)$ & $78(60.9)$ & & & \\
\hline Addiction/psychiatry & $353(54.9)$ & $171(45.2)$ & $36(28.1)$ & & & \\
\hline Other & $75(11.7)$ & $45(11.9)$ & $14(10.9)$ & & & \\
\hline Practice, No. (\%) & & & & 1,155 & 22.07 & $<.001$ \\
\hline Individual medical practice & $361(55.6)$ & $183(48.4)$ & $43(33.6)$ & & & \\
\hline Other & $288(44.4)$ & $195(51.6)$ & $85(66.4)$ & & & \\
\hline $\begin{array}{l}\text { Years prescribing buprenorphine, } \\
\text { mean (SD) }\end{array}$ & $7.0(3.9)^{a, b}$ & $6.4(3.9)$ & $6.1(3.7)$ & 1,124 & 4.90 & .008 \\
\hline Waiver type, No. (\%) & & & & 1,174 & 5.50 & .06 \\
\hline 30-patient limit & $296(44.8)$ & $143(37.4)$ & $57(43.2)$ & & & \\
\hline 100-patient limit & $364(55.2)$ & $239(62.6)$ & $75(56.8)$ & & & \\
\hline Payment type for office visits, No. (\%) & & & & 1,141 & 36.61 & $<.001$ \\
\hline Cash only & $140(21.9)$ & $67(17.9)$ & $16(12.4)$ & & & \\
\hline Private insurance but not Medicaid & $170(26.7)$ & $88(23.5)$ & $14(10.9)$ & & & \\
\hline $\begin{array}{l}\text { Medicaid (with or without private } \\
\text { insurance) }\end{array}$ & $292(45.8)$ & $205(54.8)$ & $95(73.6)$ & & & \\
\hline Other & $36(5.6)$ & $14(3.7)$ & $4(3.1)$ & & & \\
\hline Age, mean (SD), y & $55.3(12.1)$ & $55.4(10.7)$ & $56.4(9.4)$ & 1,164 & 0.51 & .60 \\
\hline Sex, No. (\%) & & & & 1,165 & 2.13 & .35 \\
\hline Male & $493(75.5)$ & $300(78.9)$ & $105(79.5)$ & & & \\
\hline Female & $160(24.5)$ & $80(21.1)$ & $27(20.5)$ & & & \\
\hline Race, No. (\%) & & & & 1,148 & 18.70 & .001 \\
\hline White & $466(72.0)$ & $302(81.0)$ & $110(85.9)$ & & & \\
\hline Asian & $100(15.5)$ & $34(9.1)$ & $10(7.8)$ & & & \\
\hline Other & $81(12.5)$ & $37(9.9)$ & $8(6.3)$ & & & \\
\hline Census division, No. (\%) & & & & 1,174 & 81.66 & $<.001$ \\
\hline New England & $62(9.4)$ & $47(12.3)$ & $17(12.9)$ & & & \\
\hline Middle Atlantic & $143(21.7)$ & $37(9.7)$ & $15(11.4)$ & & & \\
\hline East North Central & $81(12.3)$ & $49(12.8)$ & $21(15.9)$ & & & \\
\hline West North Central & $17(2.6)$ & $17(4.5)$ & $6(4.5)$ & & & \\
\hline South Atlantic & $129(19.5)$ & $85(22.3)$ & $16(12.1)$ & & & \\
\hline East South Central & $24(3.6)$ & $34(8.9)$ & $14(10.6)$ & & & \\
\hline West South Central & $45(6.8)$ & $29(7.6)$ & $5(3.8)$ & & & \\
\hline Mountain & $31(4.7)$ & $44(11.5)$ & $11(8.3)$ & & & \\
\hline Pacific & $128(19.4)$ & $40(10.5)$ & $27(20.5)$ & & & \\
\hline
\end{tabular}

US $=$ United States

Note: Groups were compared using analysis of variance (F statistic) or $\chi^{2}$ tests. Percentage may not sum to $100 \%$ due to rounding. Not all prescribers responded to all items; the $\mathrm{N}$ column represents the number of prescribers with valid data for each item.

a Significant difference with Bonferroni correction between physicians in large metropolitan areas and small metropolitan areas.

b Significant difference with Bonferroni correction between physicians in large metropolitan areas and nonmetropolitan areas. 
analyses were conducted using Stata 15.1 (StataCorp, LLC). ${ }^{26}$ Initial analyses compared physicians in the 3 locations of practice groups (ie, nonmetropolitan, small metropolitan, and large metropolitan) using analysis of variance or $\chi^{2}$ tests. Multivariate models were then estimated using the location of practice and other physician characteristics as covariates. Before estimating these multivariate models, multiple imputation by chained equations was implemented using StataCorp's "mi impute chained" command to impute missing values to reduce the bias that occurs when complete case analysis is used. ${ }^{27}$ Missing data for the study variables ranged from $0.8 \%(n=9)$ to $8.1 \%(\mathrm{n}=95)$ (see Supplemental Table 1, http://www. AnnFamMed.org/content/17/3/212/suppl/DC1/ for number of complete cases for all measures). The imputation model included all variables presented in Tables 1 to 3 and resulted in 20 imputed data sets. We then

Table 2. Buprenorphine Treatment Characteristics and Practices Among Physicians Across Locations of Practice

\begin{tabular}{|c|c|c|c|c|c|c|}
\hline & $\begin{array}{c}\text { Large } \\
\text { Metropolitan } \\
\text { Area }\end{array}$ & $\begin{array}{c}\text { Small } \\
\text { Metropolitan } \\
\text { Area }\end{array}$ & $\begin{array}{l}\text { Nonmetropolitan } \\
\quad \text { Area }\end{array}$ & $\mathbf{N}$ & $\chi^{2}$ or $\mathbf{F}$ & $\begin{array}{c}P \\
\text { Value }\end{array}$ \\
\hline New patients, in-office induction, mean \% (SD) & $43.2(41.9)$ & $47.0(42.2)$ & $47.5(41.4)$ & 1,141 & 1.23 & .29 \\
\hline New patients, at-home induction, mean \% (SD) & $37.1(41.6)$ & $35.2(41.3)$ & $28.3(38.4)$ & 1,137 & 2.46 & .09 \\
\hline $\begin{array}{l}\text { New patients already using street buprenor- } \\
\text { phine, mean \% (SD) }\end{array}$ & $19.2(23.2)^{a, b}$ & $23.7(24.4)$ & $25.0(26.2)$ & 1,136 & 6.05 & .002 \\
\hline $\begin{array}{l}\text { Patients in past year with heroin use disorder, } \\
\text { mean \% (SD) }\end{array}$ & $26.5(23.5)^{a, b}$ & $20.4(20.1)$ & $17.9(20.8)$ & 1,135 & 13.41 & $<.001$ \\
\hline $\begin{array}{l}\text { Patients in past year with prescription opioid } \\
\text { use disorder, mean \% (SD) }\end{array}$ & $51.9(27.2)^{a, b}$ & $57.1(27.0)$ & $60.0(27.4)$ & 1,134 & 7.30 & $<.001$ \\
\hline $\begin{array}{l}\text { Patients in past year with both heroin and pre- } \\
\text { scription opioid use disorders, mean \% (SD) }\end{array}$ & $22.7(19.7)$ & $22.1(19.5)$ & $24.7(22.2)$ & 1,133 & 0.82 & .44 \\
\hline $\begin{array}{l}\text { Typical frequency of office visits in initial treat- } \\
\text { ment (ie, first } 60 \text { days), No. (\%) }\end{array}$ & & & & 1,131 & & \\
\hline$\geq$ Every week & $149(23.4)$ & $121(32.9)$ & $31(24.8)$ & & 12.95 & .012 \\
\hline Every 2 weeks & $246(38.6)$ & $112(30.4)$ & $43(34.4)$ & & & \\
\hline$\leq$ Once a month & $243(38.1)$ & $135(36.7)$ & $51(40.8)$ & & & \\
\hline $\begin{array}{l}\text { Typical frequency of office visits in mainte- } \\
\text { nance treatment (ie, after } 60 \text { days) for stable } \\
\text { patients, No. (\%) }\end{array}$ & & & & 1,127 & 2.32 & .68 \\
\hline$\geq$ Every 2 weeks & $93(14.7)$ & $65(17.7)$ & $18(14.4)$ & & & \\
\hline Once a month & $473(74.5)$ & $260(70.8)$ & $91(72.8)$ & & & \\
\hline$\leq$ Every 2 months & 69 (10.9) & $42(11.4)$ & $16(12.8)$ & & & \\
\hline $\begin{array}{l}\text { Typical visit frequency in maintenance treatment } \\
\text { for unstable patients (eg, continued opioid } \\
\text { use, misusing benzodiazepines), No. (\%) }\end{array}$ & & & & 1,130 & 5.12 & .53 \\
\hline Every week & $239(37.6)$ & $151(41.0)$ & $50(39.7)$ & & & \\
\hline Every 2 weeks & $258(40.6)$ & $136(37.0)$ & $41(32.5)$ & & & \\
\hline$\leq$ Once a month & $105(16.5)$ & $58(15.8)$ & $27(21.4)$ & & & \\
\hline Patient would no longer be seen & $34(5.3)$ & $23(6.3)$ & $8(6.3)$ & & & \\
\hline $\begin{array}{l}\text { Typical buprenorphine dose for stable patients } \\
\text { in maintenance treatment, No. (\%) }\end{array}$ & & & & 1,115 & 11.46 & .08 \\
\hline$\leq 8 \mathrm{mg}$ & $188(30.0)$ & $104(28.7)$ & $31(24.6)$ & & & \\
\hline $9-12 \mathrm{mg}$ & $182(29.0)$ & $78(21.5)$ & $36(28.6)$ & & & \\
\hline $14-16 \mathrm{mg}$ & $230(36.7)$ & $161(44.5)$ & $50(39.7)$ & & & \\
\hline$>16 \mathrm{mg}$ & $27(4.3)$ & $19(5.2)$ & $9(7.1)$ & & & \\
\hline $\begin{array}{l}\text { Maximum buprenorphine dose for stable } \\
\text { patients in maintenance treatment, No. (\%) }\end{array}$ & & & & 1,102 & 5.76 & .45 \\
\hline$<16 \mathrm{mg}$ & $78(12.5)$ & $35(9.8)$ & $19(15.3)$ & & & \\
\hline $16 \mathrm{mg}$ & $204(32.8)$ & $123(34.6)$ & $43(34.7)$ & & & \\
\hline $17-24 \mathrm{mg}$ & $263(42.3)$ & $156(43.8)$ & $43(34.7)$ & & & \\
\hline$>24 \mathrm{mg}$ & 77 (12.4) & $42(11.8)$ & $19(15.3)$ & & & \\
\hline \multicolumn{7}{|c|}{$\begin{array}{l}\text { Note: Comparisons were made using } x^{2} \text { tests or } 1 \text {-way analysis of variance (F statistic). Not all prescribers responded to all items; the } N \text { column represents the number } \\
\text { of prescribers with valid data for each item. }\end{array}$} \\
\hline
\end{tabular}


used the "mi estimate" command to pool the estimates of the multivariate models from the 20 imputed data sets. Robust standard errors were estimated to account for the nesting of physicians within states.

\section{RESULTS}

Among this sample of US physicians who prescribe buprenorphine, $11.2 \%(\mathrm{n}=132)$ practiced in nonmetropolitan or rural areas, $32.5 \%(\mathrm{n}=382)$ practiced in small metropolitan areas, and $56.2 \%(n=660)$ practiced in large metropolitan areas (with a 33\% response rate among eligible physicians surveyed) (see Supplemental Table 2, http://www.AnnFamMed.org/content/17/3/212/ suppl/DC1/ for comparisons between those who responded vs the full sample surveyed). Table 1 summarizes physician characteristics by the 3 locationof-practice categories. Physicians in nonmetropolitan areas were much more likely to identify as primary care clinicians and less likely to specialize in addiction or psychiatry. Physicians in nonmetropolitan areas were less likely to prescribe buprenorphine in individual medical practice than physicians in small metropolitan or large metropolitan areas. There was also a significant difference in types of payment accepted, with physicians in nonmetropolitan areas less likely to accept cash payment only and more likely to accept Medicaid than physicians in small or large metropolitan areas.

Table 2 summarizes buprenorphine treatment practices. There were no differences between the location-of-practice groups regarding doses or office visits during the maintenance phase. A larger proportion of patients with primarily heroin use and a smaller proportion with primarily prescription opioid use were seen by physicians in large metropolitan areas compared with physicians practicing in small metropolitan areas or nonmetropolitan areas.

Table 3 summarizes adjunctive treatment use and perceptions. Physicians in nonmetropolitan areas reported a greater percentage of patients receiving counseling from external clinicians (those not associated with the respondent's practice) than did physicians in small or large metropolitan areas. There was no difference in the percentage of patients referred to more intensive levels of care. More physicians in large metropolitan areas reported that their settings were able to address complex psychiatric needs than physicians in nonmetropolitan areas.

Table 3. Psychosocial Treatment Use and Perceptions Among Buprenorphine Prescribers Across Locations of Practice

\begin{tabular}{|c|c|c|c|c|c|c|}
\hline & $\begin{array}{l}\text { Large } \\
\text { Metropolitan } \\
\text { Areas }\end{array}$ & $\begin{array}{l}\text { Small } \\
\text { Metropolitan } \\
\text { Areas }\end{array}$ & $\begin{array}{l}\text { Nonmetropolitan } \\
\text { Areas }\end{array}$ & $\mathbf{N}$ & $\chi^{2}$ or $\mathbf{F}$ & $\begin{array}{c}P \\
\text { Value }\end{array}$ \\
\hline $\begin{array}{l}\text { Patients in past year who received counseling } \\
\text { from the respondent, mean \% (SD) }\end{array}$ & $53.8(43.1)$ & $52.6(45.0)$ & $54.8(45.1)$ & 1,119 & 0.14 & .87 \\
\hline $\begin{array}{l}\text { Patients in past year who received counseling } \\
\text { from clinicians in the respondent's practice, } \\
\text { mean } \%(S D)\end{array}$ & $35.1(40.0)^{\mathrm{a}}$ & $42.2(41.8)$ & $40.5(44.2)$ & 1,108 & 3.63 & .03 \\
\hline $\begin{array}{l}\text { Patients in past year who received counseling } \\
\text { from clinicians outside of respondent's prac- } \\
\text { tice, mean \% (SD) }\end{array}$ & $39.0(32.3)^{b}$ & $35.9(31.7)^{c}$ & $46.9(36.3)$ & 1,096 & 5.20 & .006 \\
\hline $\begin{array}{l}\text { Patients in past year who received no psycho- } \\
\text { social counseling, mean \% (SD) }\end{array}$ & $13.8(21.1)$ & $10.8(19.1)$ & $10.0(17.0)$ & 1,079 & 3.60 & .03 \\
\hline $\begin{array}{l}\text { Patients in past year referred to more inten- } \\
\text { sive level of care, mean \% (SD) }\end{array}$ & $17.8(20.0)$ & $15.9(19.8)$ & $14.2(15.3)$ & 1,136 & 2.38 & .09 \\
\hline $\begin{array}{l}\text { Setting has resources to provide medical } \\
\text { services for patients with complex medical } \\
\text { problems, mean (SD) }\end{array}$ & $3.3(1.5)^{\mathrm{a}}$ & $3.6(1.4)$ & $3.6(1.4)$ & 1,148 & 3.93 & .02 \\
\hline $\begin{array}{l}\text { Setting has resources to provide psychiatric } \\
\text { services for patients with complex psychiat- } \\
\text { ric problems (eg, serious/persistent mental } \\
\text { illness), mean (SD) }\end{array}$ & $3.3(1.5)^{\mathrm{b}}$ & $3.2(1.5)$ & $2.9(1.4)$ & 1,148 & 4.88 & .008 \\
\hline $\begin{array}{l}\text { Setting has resources to provide social ser- } \\
\text { vices for patients with complex social prob- } \\
\text { lems (eg, unstable housing, criminal justice } \\
\text { involvement, unemployment), mean (SD) }\end{array}$ & $2.7(1.3)$ & $2.7(1.3)$ & $2.7(1.3)$ & 1,142 & 0.19 & .82 \\
\hline \multicolumn{7}{|c|}{$\begin{array}{l}\text { Note: Comparisons were made using } x^{2} \text { tests or } 1 \text {-way analysis of variance ( } F \text { statistic). Not all prescribers responded to all items; the } N \text { column represents the number } \\
\text { of prescribers with valid data for each item. }\end{array}$} \\
\hline $\begin{array}{l}\text { a Significant difference with Bonferroni correction betv } \\
\text { bSignificant difference with Bonferroni correction betv } \\
\text { 'Significant difference with Bonferroni correction beth } \\
\text { d Likert scale ranging from } 1=\text { strongly disagree to } 5\end{array}$ & $\begin{array}{l}\text { een physicians in large } \\
\text { een physicians in large } \\
\text { een physicians in small } \\
=\text { strongly agree. }\end{array}$ & $\begin{array}{l}\text { metropolitan areas an } \\
\text { metropolitan areas an } \\
\text { metropolitan areas an }\end{array}$ & $\begin{array}{l}\text { small metropolitan areas. } \\
\text { nonmetropolitan areas. } \\
\text { nonmetropolitan areas. }\end{array}$ & & & \\
\hline
\end{tabular}


A series of multivariate models were estimated to examine whether differences between the 3 groups remained significant after controlling for physicians' professional and demographic differences. The differences across locations of practice in the percentage of new patients who were already using illicit buprenorphine, the frequency of office visits during the initial phase of treatment, resources to address complex medical and psychiatric needs, and the percentage of patients receiving counseling from external clinicians were no longer significant in the multivariate models (data not shown).

Table 4 presents all of the adjusted analyses for which location of practice remained significant after controlling for other physician characteristics (ie, variables in Table 1). Physicians in small metropolitan areas and nonmetropolitan areas reported both significantly lesser percentages of patients with heroin use disorder (column 1) and greater percentages of patients with prescription OUD (column 2) compared with physicians in large metropolitan areas. Physicians in small metropolitan areas had a significantly greater percentage of patients receiving counseling from other clinicians in the respondent's practice (column 3) and had a significantly lesser percentage of patients not receiving counseling (column 4) than physicians in large metropolitan areas. Results regarding location of practice were similar when the models were reestimated using listwise deletion.

\section{DISCUSSION}

With intense interest and efforts underway to increase the number of buprenorphine prescribers in the United States, particularly in rural areas, it is critical to understand who is currently providing care in rural areas, what their practices are like, and how they may differ from urban areas with typically greater resources. In this study examining a national sample of active buprenorphine prescribers, nonmetropolitan physicians were almost twice as likely to be primary care physicians compared with those in large metropolitan areas and were much less likely to be specialists with addiction or psychiatry backgrounds. Consistent with this emphasis on primary care, nonmetropolitan physicians were also much more likely to accept Medicaid and less likely to work in individual practice. Of note, clinicians in small metropolitan areas showed characteristics in between those in nonmetropolitan areas and those in large metropolitan areas. These findings suggest that there is likely a continuum of variation in physician characteristics that corresponds to the rural/urban continuum.

Efforts to increase the numbers buprenorphine prescribers and the numbers of patients treated in more rural areas should focus on supporting rural primary care clinicians. A number of models have been examined for delivering buprenorphine treatment in primary care, with a few that have been examined in rural settings including the Extension for Community Healthcare Outcomes and hub-and-spoke models. ${ }^{28-30}$ There have also been very promising local models including the integration of behavioral health clinicians on site. ${ }^{31}$ Further studies are needed to specifically examine the effectiveness of these and other buprenorphine treatment models in rural areas where patients are not only traveling much longer distances to reach treatment but may also differ in many other aspects including views about behavioral and mental health treatment. ${ }^{32}$

The present study also provides some of the first data across US prescribers on buprenorphine treatment practices during the induction and maintenance periods. On average, there were surprisingly few differences in buprenorphine-prescribing practices across locations of practice. There was variation in frequency of visits for patients early in treatment, but the majority of physicians across rural/urban groups saw patients who were stable monthly. There were no differences in frequency of visits for stabilized patients and no differences in dosing for patients, and prescribers reported that only a small proportion of patients received doses of buprenorphine $>24 \mathrm{mg}$. These practices are consistent with buprenorphine practice guidelines that typically recommend minimizing the use of buprenorphine doses $>24 \mathrm{mg}$ because greater doses might increase the risk of diversion. ${ }^{16,17}$ Consistent with guidelines, ${ }^{17}$ physicians also reported using more frequent visits, often weekly or every 2 weeks, for patients who are unstable (ie, relapse on opioids or who are using other substances). Many of these practices, however, may require substantial clinical resources. Successful treatment models, particularly in rural primary care settings, may need to incorporate multidisciplinary staffing that provides not only medication prescribing but also additional monitoring, support, and counseling services that are key to addressing the needs of the patient population.

Finally, nonmetropolitan physicians reported that on average a lesser percentage of patients did not receive psychosocial treatment but reported greater challenges with respect to resources to provide services for patients with complex psychiatric problems, though differences were no longer significant after adjusting for physician characteristics. Although there may be lower availability and use of psychotherapy in rural areas broadly, ${ }_{1}^{13,33}$ and limited access to psychotherapy may be a barrier to more patients receiving buprenorphine treatment, ${ }^{18}$ rural physicians who prescribe buprenorphine might also 
Table 4. Negative Binomial Regression Models of Location of Practice and Physician Characteristics and Association With Buprenorphine Treatment

\begin{tabular}{|c|c|c|c|c|}
\hline & $\begin{array}{c}\text { Model } 1 \\
\text { Patients in Past } \\
\text { Year With Heroin } \\
\text { Use Disorder } \\
\text { IRR }(95 \% \mathrm{Cl}) \\
\end{array}$ & $\begin{array}{c}\text { Model } 2 \\
\text { Patients in Past Year } \\
\text { With Prescription } \\
\text { Opioid Use } \\
\text { Disorder } \\
\text { IRR }(95 \% \mathrm{Cl}) \\
\end{array}$ & $\begin{array}{l}\text { Model } 3 \\
\text { Patients in Past Year } \\
\text { Who Received Counseling } \\
\text { From Clinicians in the } \\
\text { Respondent's Practice } \\
\text { IRR }(95 \% \mathrm{Cl})\end{array}$ & $\begin{array}{c}\text { Model } 4 \\
\text { Patients in Past } \\
\text { Year Who Received } \\
\text { No Counseling } \\
\text { IRR }(95 \% \mathrm{CI}) \\
\end{array}$ \\
\hline \multicolumn{5}{|l|}{ Rural-urban continuum } \\
\hline Large metropolitan area & Reference & Reference & Reference & Reference \\
\hline Small metropolitan area & $0.753(0.651,0.869)^{\mathrm{a}}$ & $1.076(1.000,1.158)^{c}$ & $1.219(1.021,1.455)^{c}$ & $0.732(0.570,0.942)^{c}$ \\
\hline Nonmetropolitan area & $0.641(0.506,0.812)^{\mathrm{a}}$ & $1.227(1.118,1.347)^{\mathrm{a}}$ & $1.094(0.886,1.351)$ & $0.675(0.447,1.020)$ \\
\hline \multicolumn{5}{|l|}{ Medical specialty } \\
\hline Primary care & Reference & Reference & Reference & Reference \\
\hline Addiction or psychiatry & $1.113(0.965,1.284)$ & $0.917(0.872,0.966)^{b}$ & $1.927(1.591,2.333)^{\mathrm{a}}$ & $0.383(0.308,0.475)^{a}$ \\
\hline Other & $0.804(0.587,1.100)$ & $1.117(1.000,1.248)$ & $1.177(0.895,1.548)$ & $0.933(0.755,1.152)$ \\
\hline \multicolumn{5}{|l|}{ Practice } \\
\hline $\begin{array}{l}\text { Individual medical } \\
\text { practice }\end{array}$ & $0.879(0.767,1.007)$ & $1.105(1.020,1.197)^{c}$ & $0.486(0.418,0.566)^{\mathrm{a}}$ & $1.045(0.819,1.332)$ \\
\hline Other & Reference & Reference & Reference & Reference \\
\hline $\begin{array}{l}\text { Years prescribing } \\
\text { buprenorphine }\end{array}$ & $0.989(0.973,1.005)$ & $1.006(0.998,1.015)$ & $0.985(0.968,1.003)$ & $1.003(0.978,1.029)$ \\
\hline \multicolumn{5}{|l|}{ Waiver type } \\
\hline 30-patient limit & Reference & Reference & Reference & Reference \\
\hline 100-patient limit & $1.206(1.037,1.402)^{c}$ & $0.939(0.887,0.993)^{c}$ & $1.094(0.971,1.232)$ & $1.218(0.968,1.534)$ \\
\hline \multicolumn{5}{|l|}{$\begin{array}{l}\text { Payment type for office } \\
\text { visits }\end{array}$} \\
\hline Cash only & Reference & Reference & Reference & Reference \\
\hline $\begin{array}{l}\text { Private insurance but } \\
\text { not Medicaid }\end{array}$ & $0.837(0.682,1.028)$ & $1.115(1.023,1.215)^{c}$ & $1.114(0.799,1.553)$ & $0.960(0.720,1.279)$ \\
\hline $\begin{array}{l}\text { Medicaid (with or with- } \\
\text { out private insurance) }\end{array}$ & $1.246(1.045,1.484)^{c}$ & $0.873(0.803,0.950)^{b}$ & $1.409(0.981,2.024)$ & $0.998(0.751,1.326)$ \\
\hline Other & $0.954(0.696,1.306)$ & $0.940(0.799,1.104)$ & $1.330(0.956,1.851)$ & $1.394(0.713,2.724)$ \\
\hline Age & $0.999(0.994,1.004)$ & $1.001(0.999,1.003)$ & $0.998(0.993,1.003)$ & $0.988(0.977,0.999)^{c}$ \\
\hline \multicolumn{5}{|l|}{ Sex } \\
\hline Male & Reference & Reference & Reference & Reference \\
\hline Female & $1.099(0.969,1.246)$ & $0.978(0.916,1.044)$ & $0.992(0.853,1.154)$ & $0.752(0.556,1.016)$ \\
\hline \multicolumn{5}{|l|}{ Race } \\
\hline White & Reference & Reference & Reference & Reference \\
\hline Asian & $0.898(0.767,1.051)$ & $1.026(0.969,1.087)$ & $0.893(0.716,1.113)$ & $1.119(0.848,1.477)$ \\
\hline Other & $1.107(0.872,1.406)$ & $0.976(0.877,1.086)$ & $0.770(0.615,0.964)^{c}$ & $0.894(0.630,1.268)$ \\
\hline \multicolumn{5}{|l|}{ Census division } \\
\hline New England & Reference & Reference & Reference & Reference \\
\hline Middle Atlantic & $1.057(0.796,1.403)$ & $1.024(0.850,1.233)$ & $0.910(0.706,1.173)$ & $0.937(0.662,1.327)$ \\
\hline East North Central & $0.943(0.684,1.299)$ & $1.160(0.910,1.478)$ & $1.074(0.849,1.359)$ & $0.852(0.477,1.521)$ \\
\hline West North Central & $0.668(0.492,0.908)^{c}$ & $1.400(1.156,1.695)^{\mathrm{a}}$ & $0.900(0.694,1.167)$ & $0.891(0.546,1.452)$ \\
\hline South Atlantic & $0.683(0.476,0.979)^{c}$ & $1.313(1.035,1.667)^{c}$ & $1.082(0.883,1.326)$ & $1.359(0.879,2.101)$ \\
\hline East South Central & $0.580(0.332,1.015)$ & $1.429(1.107,1.845)^{b}$ & $1.365(0.975,1.913)$ & $1.057(0.488,2.288)$ \\
\hline West South Central & $0.592(0.435,0.807)^{b}$ & $1.527(1.278,1.826)^{\mathrm{a}}$ & $1.237(0.803,1.904)$ & $1.517(1.037,2.219)^{c}$ \\
\hline Mountain & $0.918(0.633,1.332)$ & $1.212(0.992,1.482)$ & $0.923(0.729,1.168)$ & $1.050(0.672,1.640)$ \\
\hline Pacific & $0.993(0.705,1.400)$ & $1.168(0.963,1.415)$ & $0.923(0.773,1.102)$ & $1.380(0.961,1.981)$ \\
\hline Constant & $29.374(20.616,41.853)$ & $41.332(33.698,50.696)$ & $30.001(18.583,48.433)$ & $30.427(12.756,72.573)$ \\
\hline \multicolumn{5}{|l|}{ IRR = incidence rate ratio. } \\
\hline $\begin{array}{l}\text { Note: These models present ad } \\
\text { Table 1). Models represent the } \\
\text { a } P=<.001 \text { (2-tailed tests). } \\
\text { b } P=<.01 \text { (2-tailed tests). } \\
\text { c } P=<.05 \text { (2-tailed tests). }\end{array}$ & $\begin{array}{l}\text { sted analyses in which locations } \\
\text { poled estimates from } 20 \text { impute }\end{array}$ & $\begin{array}{l}\text { of practice remained significant } \\
\text { data sets }(n=1,174) \text {. Robust sta }\end{array}$ & $\begin{array}{l}\text { fer controlling for other physician char } \\
\text { ndard errors were used to adjust for phy }\end{array}$ & $\begin{array}{l}\text { teristics (ie, variables in } \\
\text { ician clustering within states. }\end{array}$ \\
\hline
\end{tabular}


be more stringent about recommending additional psychosocial treatment. A recent qualitative study of rural buprenorphine-prescribing physicians identified strategies used to overcome barriers to delivering buprenorphine treatment. ${ }^{34}$ Concerns about diversion and misuse and not wanting to be perceived as being inconsistent or too lenient in a small community, which could attract patients who may be perceived as potentially taking advantage of the situation, encouraged physicians to establish clear requirements for treatment and included many who required patients to attend some form of psychosocial treatment especially at the beginning of treatment. ${ }^{34}$ Despite these challenges, many physicians also reported high satisfaction and fulfillment with respect to delivering this important treatment. ${ }^{34}$ Additional studies are needed to further understand variation in treatment practices and the reasoning behind specific practices and also, importantly, to further understand patient perceptions and outcomes.

There are several limitations to the present study. All data relied on physician self-report, and physicians might be less likely to report practices that are not consistent with recommendations for buprenorphine treatment. Surveys were confidential, however, and there are no other data available that have examined these important buprenorphine treatment practices. The response rate is also a limitation, though it is a common challenge regarding physician surveys. ${ }^{35,36}$ Our sampling strategy resulted in respondents being generally well distributed across the United States. Comparing respondents to all physicians surveyed on 5 key characteristics, we found that they were generally similar (Supplemental Table 2). Because of our focus on active prescribers, however, physicians with a 100 -patient waiver were more likely to be eligible for the study, and they also comprised a greater proportion of respondents $(57.8 \%)$ compared to all physicians surveyed (52.3\%). This is consistent with prior survey studies of buprenorphine prescribers ${ }_{1}^{19}$ but this does not exclude the possibility of differences in unmeasured characteristics. For example, if physicians who adhere to recommended practices are more likely to respond, this might skew the results toward concordance with recommended practices; however, we expect this would occur across the rural/urban continuum.

\section{CONCLUSIONS}

Active buprenorphine prescribers in nonmetropolitan areas were much more likely to be primary care clinicians compared with those in more urban settings, but on average, treatment practices and quality were remarkably similar across physicians in rural/urban areas. Buprenorphine prescribers report seeing patients relatively frequently and often provide or refer patients to adjunctive psychosocial treatment. As buprenorphine treatment becomes more available, it is critical to continue to assess quality of care and variation in quality across physicians and treatment settings.

To read or post commentaries in response to this article, see it online at http://www.AnnFamMed.org/content/17/3/212.

Key words: opioid use disorder; opioid-related disorders; buprenorphine; rural; rural health; nonmetropolitan; treatment quality

Submitted August 19, 2018; submitted, revised, December 24, 2018; accepted January 31, 2019.

Funding support: This research was supported by a grant from the National Institute on Drug Abuse (NIDA R33DA035641), within the National Institutes of Health (NIH). Use of REDCap for data management was supported by NIH's National Center for Advancing Translational Sciences (NCATS UL1TR000117). The authors are solely responsible for this manuscript, which does not represent the official views of NIDA, NIH, or NCATS.

Previous presentations: This work was presented at a workshop at the American Academy of Addiction Psychiatry annual meeting, December 6-9, 2018, Bonita Springs, Florida.

Supplementary materials: Available at http://www.AnnFamMed. org/content/17/3/212/suppl/DC1/.

\section{References}

1. Han B, Compton WM, Blanco C, Crane E, Lee J, Jones CM. Prescription opioid use, misuse, and use disorders in U.S. adults: 2015 National Survey on Drug Use and Health. Ann Intern Med. 2017; 167(5):293-301.

2. Martins SS, Sarvet A, Santaella-Tenorio J, Saha T, Grant BF, Hasin DS. Changes in US lifetime heroin use and heroin use disorder: prevalence from the 2001-2002 to 2012-2013 National Epidemiologic Survey on Alcohol and Related Conditions. JAMA Psychiatry. 2017;74(5):445-455.

3. Bohnert AS, Ilgen MA, Ignacio RV, McCarthy JF, Valenstein M, Blow FC. Risk of death from accidental overdose associated with psychiatric and substance use disorders. Am J Psychiatry. 2012;169(1):64-70.

4. Bohnert KM, Ilgen MA, Louzon S, McCarthy JF, Katz IR. Substance use disorders and the risk of suicide mortality among men and women in the US Veterans Health Administration. Addiction. 2017; 112(7):1193-1201.

5. Larochelle MR, Bernson D, Land T, et al. Medication for opioid use disorder after nonfatal opioid overdose and association with mortality: a cohort study. Ann Intern Med. 2018;169(3):137-145.

6. Nielsen S, Larance B, Lintzeris N. Opioid agonist treatment for patients with dependence on prescription opioids. JAMA. 2017; 317(9):967-968.

7. Mattick RP, Breen C, Kimber J, Davoli M. Buprenorphine maintenance versus placebo or methadone maintenance for opioid dependence. Cochrane Database Syst Rev. 2014;(2):CD002207.

8. Andrilla CHA, Moore TE, Patterson DG, Larson EH. Geographic distribution of providers with a DEA waiver to prescribe buprenorphine for the treatment of opioid use disorder: a 5-year update. J Rural Health. 2019;35(1):108-112.

9. Sigmon SC. Access to treatment for opioid dependence in rural America: challenges and future directions. JAMA Psychiatry. 2014; 71(4):359-360. 
10. Levin FR, Cates-Wessel K. Commentary: providing technical assistance for the state targeted response for opioid use disorders: time is of the essence. Am J Addict. 2018;27(3):158-160.

11. Johnson K, Jones C, Compton W, et al. Federal response to the opioid crisis. Curr HIV/AIDS Rep. 2018;15(4):293-301.

12. Romo E, Ulbricht CM, Clark RE, Lapane KL. Correlates of specialty substance use treatment among adults with opioid use disorders. Addict Behav. 2018;86:96-103.

13. Andrilla CHA, Patterson DG, Garberson LA, Coulthard C, Larson EH. Geographic variation in the supply of selected behavioral health providers. Am J Prev Med. 2018;54(6S3):S199-S207.

14. Wu LT, Zhu H, Swartz MS. Treatment utilization among persons with opioid use disorder in the United States. Drug Alcohol Depend. 2016;169:117-127.

15. Fortney J, Rost K, Zhang M, Warren J. The impact of geographic accessibility on the intensity and quality of depression treatment. Med Care. 1999;37(9):884-893.

16. American Society of Addiction Medicine. National practice guideline for the use of medications in the treatment of addiction involving opioid use. https://www.asam.org/resources/guidelines-andconsensus-documents/npg. Adopted Jun 1, 2015. Accessed Mar 15, 2019.

17. Substance Abuse and Mental Health Services Administration. Medications for opioid use disorder. Treatment Improvement Protocol 63. https://store.samhsa.gov/product/TIP-63-Medications-for-OpioidUse-Disorder-Full-Document-Including-Executive-Summary-andParts-1-5-/SMA18-5063FULLDOC. Published Feb 2018. Accessed Mar 15, 2019

18. Andrilla CHA, Coulthard C, Larson EH. Barriers rural physicians face prescribing buprenorphine for opioid use disorder. Ann Fam Med. 2017;15(4):359-362.

19. Andrilla CHA, Coulthard C, Patterson DG. Prescribing practices of rural physicians waivered to prescribe buprenorphine. Am J Prev Med. 2018;54(6S3):S208-S214.

20. Knudsen HK, Lofwall MR, Walsh SL, Havens JR, Studts JL. Physicians' decision-making when implementing buprenorphine with new patients: conjoint analyses of data from a cohort of current prescribers. J Addict Med. 2018;12(1):31-39.

21. Lin LA, Lofwall MR, Walsh SL, Gordon AJ, Knudsen HK. Perceptions and practices addressing diversion among US buprenorphine prescribers. Drug Alcohol Depend. 2018;186:147-153.

22. United States Department of Agriculture. Economic Research Service. Rural Urban Continuum Codes. https://www.ers.usda.gov/dataproducts/rural-urban-continuum-codes/. Accessed Apr 23, 2018.

23. United States Department of Housing and Urban Development. HUD USPS ZIP Code Crosswalk Files. https://www. huduser.gov/ portal/datasets/usps_crosswalk.html. Accessed Apr 23, 2018.
24. United States Census Bureau. Census regions and divisions of the United States. https://www2.census.gov/geo/pdfs/maps-data/maps/ reference/us_regdiv.pdf. Accessed Jul 30, 2018.

25. Harris PA, Taylor R, Thielke R, Payne J, Gonzalez N, Conde JG. Research electronic data capture (REDCap)--a metadata-driven methodology and workflow process for providing translational research informatics support. J Biomed Inform. 2009;42(2):377-381.

26. Stata Multiple-Imputation Reference Manual; Release 15. College Station, TX: StataCorp; 2017.

27. Allison PD. Missing Data. Thousand Oaks, CA: SAGE Publications Ltd; 2002.

28. Lagisetty P, Klasa K, Bush C, Heisler M, Chopra V, Bohnert A. Primary care models for treating opioid use disorders: what actually works? A systematic review. PLoS One. 2017;12(10):e0186315.

29. Korthuis PT, McCarty D, Weimer M, et al. Primary care-based models for the treatment of opioid use disorder: a scoping review. Ann Intern Med. 2017;166(4):268-278.

30. Rawson RA. Vermont hub-and-spoke model of care for opioid use disorders: an evaluation. Vermont Center on Behavior \& Health. http://www.healthvermont.gov/sites/default/files/documents/pdf/ ADAP_Hub_and_Spoke_Evaluation_2017_1.pdf. Published Dec 2017. Accessed Aug 9, 2018.

31. Cantone RE, Fleishman J, Garvey B, Gideonse N. Interdisciplinary management of opioid use disorder in primary care. Ann Fam Med. 2018;16(1):83.

32. Rost K, Fortney J, Fischer E, Smith J. Use, quality, and outcomes of care for mental health: the rural perspective. Med Care Res Rev. 2002;59(3):231-265, discussion 266-271.

33. Fortney JC, Harman JS, Xu S, Dong F. The association between rural residence and the use, type, and quality of depression care. J Rural Health. 2010;26(3):205-213.

34. Andrilla CHA, Moore TE, Patterson DG. Overcoming barriers to prescribing buprenorphine for the treatment of opioid use disorder: recommendations from rural physicians. J Rural Health. 2019;35(1): 113-121.

35. Keto J, Jokelainen J, Timonen M, Linden K, Ylisaukko-oja T. Physicians discuss the risks of smoking with their patients, but seldom offer practical cessation support. Subst Abuse Treat Prev Policy. 2015; 10:43.

36. Macalino GE, Sachdev DD, Rich JD, et al. A national physician survey on prescribing syringes as an HIV prevention measure. Subst Abuse Treat Prev Policy. 2009;4:13. 